[Med. Entomol. Zool. Vol. 59 No. 3 p. 171-179 2008]

\title{
A new species of Simulium (Gomphostilbia) (Diptera: Simuliidae) from Taiwan
}

\author{
Yao-Te HuAng and Hiroyuki TAKaOKa \\ Department of Infectious Disease Control, Faculty of Medicine, Oita University, \\ Hasama, Yufu City, Oita, 879-5593 Japan
}

(Received: 20 May 2008; Accepted: 1 July 2008)

\begin{abstract}
Simulium (Gomphostilbia) syuhaiense sp. nov. is described from reared adult, pupal and mature larval specimens collected from Pingtung, Taiwan. This new species is placed in the batoense species-group within the subgenus Gomphostilbia and is distinguished from known related species by the elongate female sensory vesicle.
\end{abstract}

Key words: black fly, Gomphostilbia, Simuliidae, Taiwan

The black fly fauna of Taiwan consists of 23 species of the genus Simulium which were placed in the following six subgenera: one in Eusimulium, two in Gomphostilbia, one in Montisimulium, five in Nevermannia, 13 in Simulium and one in Wallacellum (Chung, 1986; Shiraki, 1935; Takaoka, 1979; Takaoka and Huang, 2006).

Two known Taiwanese species of the subgenus Gomphostilbia, S. (G.) metatarsale Brunetti and $S$. (G.) tuenense Takaoka, belong to the ceylonicum species-group which is characterized by the enlarged male hind basitarsus (Takaoka, 2003; unpublished data). Recently we collected one more species of the subgenus Gomphostilbia from Pingtung County, southern Taiwan, which is placed in the batoense species-group defined by Takaoka (2003). In this paper we describe this species as new to science on the basis of reared adult, pupal and larval specimens.

The terms for morphological features used here follow those of Takaoka (2003). Holotype and paratype specimens of the new species are deposited at the Department of Infectious Disease Control, Faculty of Medicine, Oita University, Oita, Japan.

\section{Simulium (Gomphostilbia) syuhaiense sp. nov.}

DESCRIPTION. Female. Body length 1.8$2.1 \mathrm{~mm}$. Head. Slightly narrower than width of thorax. Frons black, shiny when illuminated at certain angle of light, grayish-white pruinose in particular near antennal bases when illuminated at certain angle of light, densely covered with yellowish-white scalelike recumbent short hairs interspersed with few dark simple longer hairs along each lateral margin; frontal ratio $1.62-1.71: 1.00: 2.00-$ 2.18; frons-head ratio $1.00: 4.00-4.98$. Frontoocular area (Fig. 1A) well developed, narrow, directed dorsolaterally. Clypeus brownishblack to black, slightly shiny and grayishwhite pruinose when illuminated at certain angle of light, densely covered with yellowishwhite scale-like recumbent short hairs interspersed with about 10 dark longer hairs on each side. Labrum 0.64 times as long as clypeus. Antenna composed of scape, pedicel and 9 flagellomeres, brownish-black except scape, pedicel, and basal $1 / 3$ to $1 / 2$ of 1 st flagellomere yellow when viewed dorsally (1st flagellomere yellow on basal $1 / 2$ to all when viewed ventrally). Maxillary palp composed of 5 segments, medium brown, proportional lengths of $3 \mathrm{rd}, 4 \mathrm{th}$, and 5 th segments 1.00 : 1.13-1.15: 2.41-2.63; 3 rd segment (Fig. 1 B) somewhat swollen; sensory vesicle (Fig. 1B) 


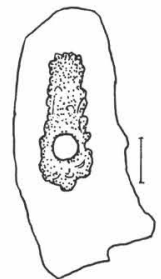

B
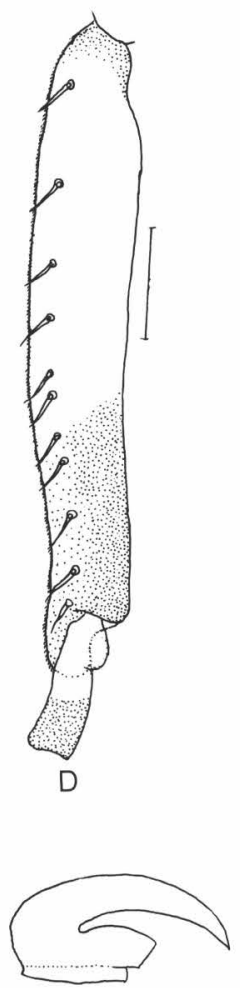

E
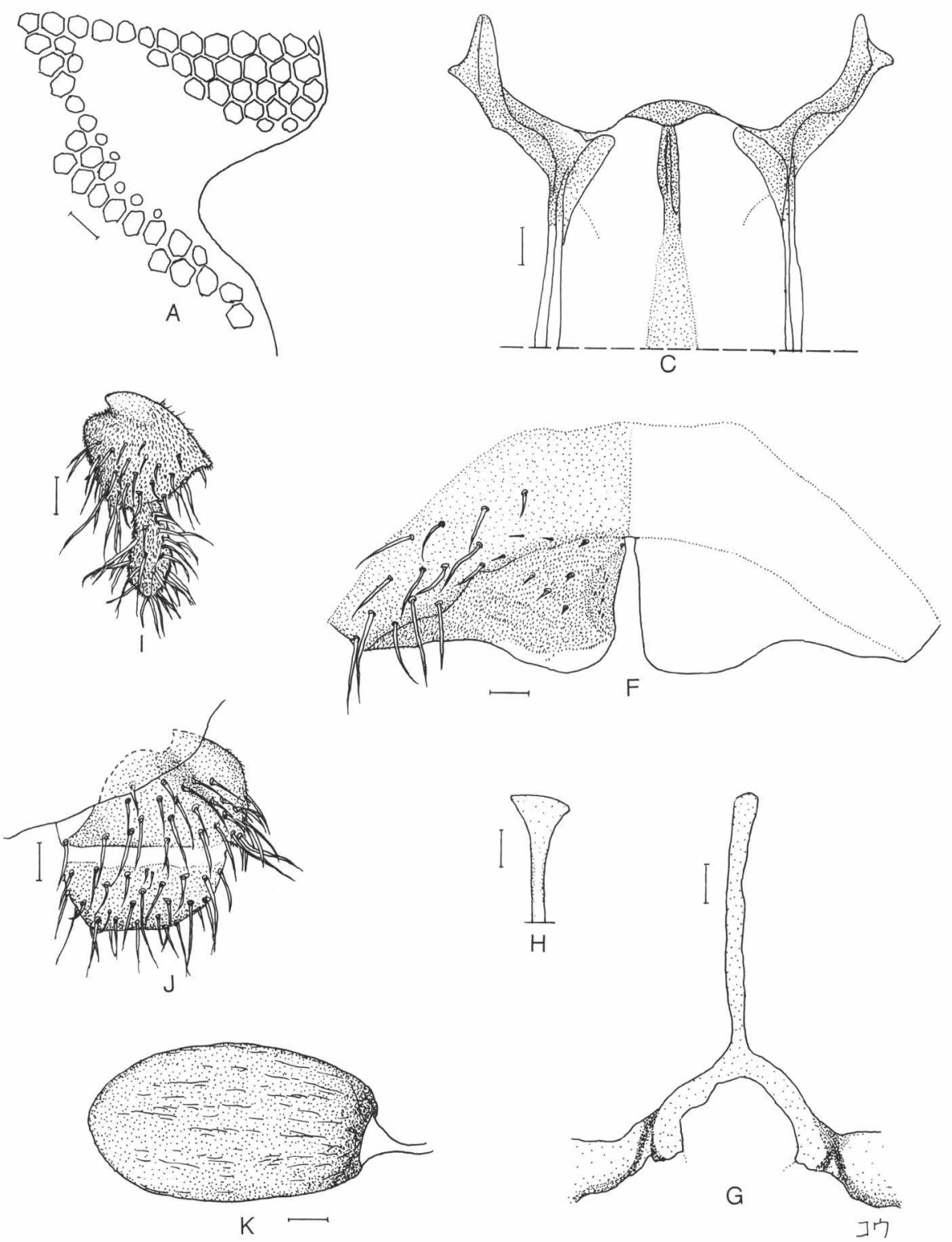

Fig. 1. Female of Simulium (Gomphostilbia) syuhaiense sp. nov. A, fronto-ocular area (right side); B, 3rd segment of maxillary palp with sensory vesicle (right side and front view); C, cibarium; D, basitarsus and 2nd tarsal segment of hind leg showing calcipala and pedisulcus (left side and outer view); E, claw; F, sternite 8 and ovipositor valves in situ (ventral view); G, genital fork (ventral view); H, inflated apex of stem of genital fork; I and J, paraprocts and cerci in situ (right side; I, ventral view; J, lateral view); K, spermatheca (lateral view). Scale bars. $0.1 \mathrm{~mm}$ for $\mathrm{D} ; 0.02 \mathrm{~mm}$ for $\mathrm{A}-\mathrm{C}$ and $\mathrm{F}-\mathrm{J} ; 0.01 \mathrm{~mm}$ for E.

elongate, 0.56-0.64 times as long as 3rd segment, with medium-sized opening apically. Maxillary lacinia with $12-13$ inner and 16 outer teeth. Mandible with 21 inner and 10-12 outer teeth. Cibarium (Fig. 1C) medially form- ing sclerotized plate folded forward from posterior margin, with moderately sclerotized medial longitudinal ridge. Thorax. Scutum black, shiny, thinly grayish-white to bluish pruinose with 3 faint non-pruinose long- 
itudinal vittae (1 medial and 2 submedial) when illuminated dorsally and viewed anteriorly or posteriorly, densely covered with yellowish-white scale-like recumbent hairs except 3 non-pruinose longitudinal vittae densely covered with dark brown scale-like recumbent hairs and prescutellar area interspersed with several dark brown simple longer hairs. Scutellum dark brown, shiny and grayish-white pruinose when illuminated at certain angle of light, covered with yellowishwhite short hairs and dark brown long upright hairs along posterior margin. Postnotum dark brown, shiny and grayish-white pruinose when illuminated at certain angle of light, and bare. Pleural membrane bare. Katepisternum dark brown, longer than deep, shiny, moderately covered with dark fine short hairs as well as whitish fine short hairs. Legs. Foreleg: coxa yellow though outer surface somewhat darkened; trochanter medium brown except inner surface yellow; femur medium brown with apical cap dark brown; tibia dark brown with extreme base yellow and medial portion of outer surface widely light brown, densely covered with whitish short hairs widely on outer surface which are brilliantly shiny when illuminated at certain angle of light; tarsus black, with moderate dorsal hair crest; basitarsus moderately dilated, 5.82 times as long as its greatest width. Midleg: coxa dark brown except posterior surface brownishblack; trochanter light to medium brown; femur medium brown with apical cap dark brown; tibia dark brown except extreme base yellow, densely covered with whitish fine hairs on basal $3 / 4$ of outer surface; tarsus brownishblack except basal $1 / 3$ to $1 / 2$ yellow (its border not well defined). Hind leg: coxa medium to dark brown; trochanter dark yellow; femur medium to dark brown with base yellow; tibia dark brown except base yellowish-white, densely covered with whitish fine hairs on basal $3 / 5$ on outer and posterior surface; tarsus (Fig. 1D) dark brown to brownish-black except little less than basal $2 / 3$ of basitarsus (though base dark brown) and little more than basal $1 / 2$ of 2 nd tarsal segment yellowish-white; basitarsus narrow, nearly parallel-sided, 5.67 times as long as wide, and 0.67 and 0.57 times as wide as greatest widths of tibia and femur, respectively; calcipala nearly as long as wide, and 0.47 times as wide as greatest width of basitarsus. Pedisulcus well marked. Claw (Fig.
1E) with large basal tooth 0.52 times as long as claw. Wing. Length $1.8-2.1 \mathrm{~mm}$. Costa with dark spinules and hairs. Subcosta with dark hairs except apical 1/4 bare. Hair tuft on stem vein dark brown. Basal portion of radius fully haired; $\mathrm{R}_{1}$ with dark spinules and hairs; $\mathrm{R}_{2}$ with hairs only. Basal cell absent. Abdomen. Basal scale light to medium brown, with fringe of yellowish-white hairs. Dorsal surface of abdomen brownish-black except tergite of segment 2 light brown, moderately covered with dark short to long hairs; tergite of segment 2 shiny and somewhat bluish iridescent when illuminated at certain angle of light, and tergites of segments 6-9 shiny, while those of segments 3-5 all dull; ventral surface of segment 2 entirely whitish-yellow, and those of other segments dark brown to brownish-black; sternal plate on segment 7 undeveloped. Genitalia. Sternite 8 (Fig. 1F) bare medially, with 14 or 15 mediumlong to very long hairs together with few to several short slender hairs on each side. Ovipositor valves (Fig. $1 \mathrm{~F}$ ) triangular, with round medioposterior corners, thin, membranous, moderately covered with microsetae interspersed with 4 or 5 short setae; inner margins very slightly sinuous, slightly sclerotized, and moderately separated from each other. Genital fork (Fig. 1G) of usual inverted-Y form, with slender stem (apex inflated in 1 female-Fig. 1 $\mathrm{H}$ ); arms of moderate width and moderately folded medially. Paraproct in ventral view (Fig. 1I) nearly triangular, pointed medially, with about 7 sensilla on anteromedial surface; paraproct in lateral view (Fig. 1J) somewhat produced ventrally, 0.76 times as long as wide, with 24-30 medium-long to long hairs on ventral and lateral surfaces. Cercus in lateral view (Fig. 1J) short, rounded posteriorly, 0.57 times as long as wide. Spermatheca (Fig. 1K) ellipsoidal, 1.73-1.89 times as long as its greatest width, well sclerotized except duct and small area near juncture with duct unsclerotized, and with many fissures on surface; internal setae absent; both accessory ducts slender, slightly larger in diameter than major one.

Male. Body length $2.1 \mathrm{~mm}$. Head. Wider than thorax. Upper eye consisting of 17 or 18 vertical columns and 17 horizontal rows of large facets. Face dark brown, grayish pruinose. Clypeus black, whitish to bluish pruinose, densely covered with golden yellow scale-like short to medium-long hairs (mostly directed upwards) interspersed with several 


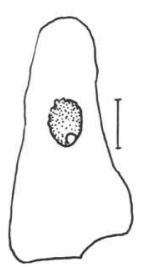

A

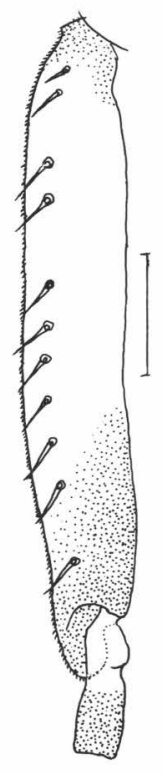

B
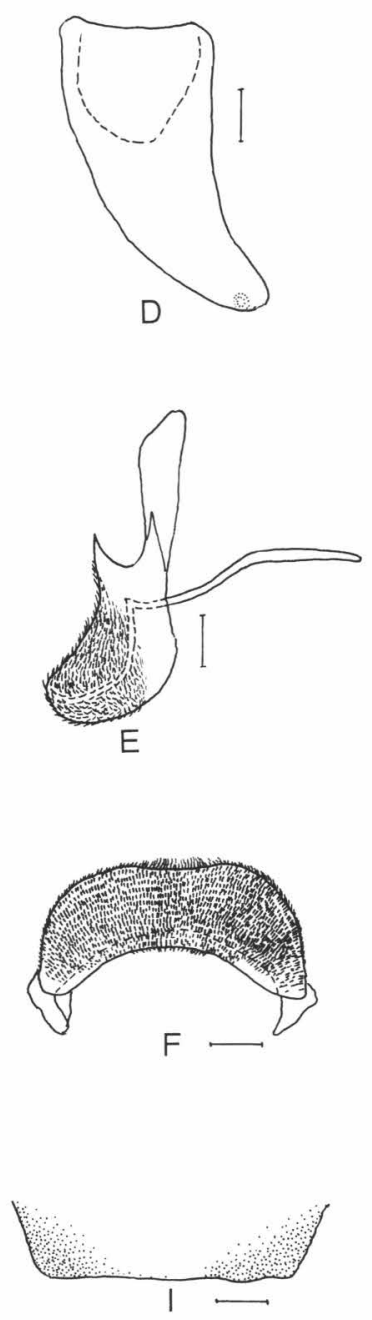
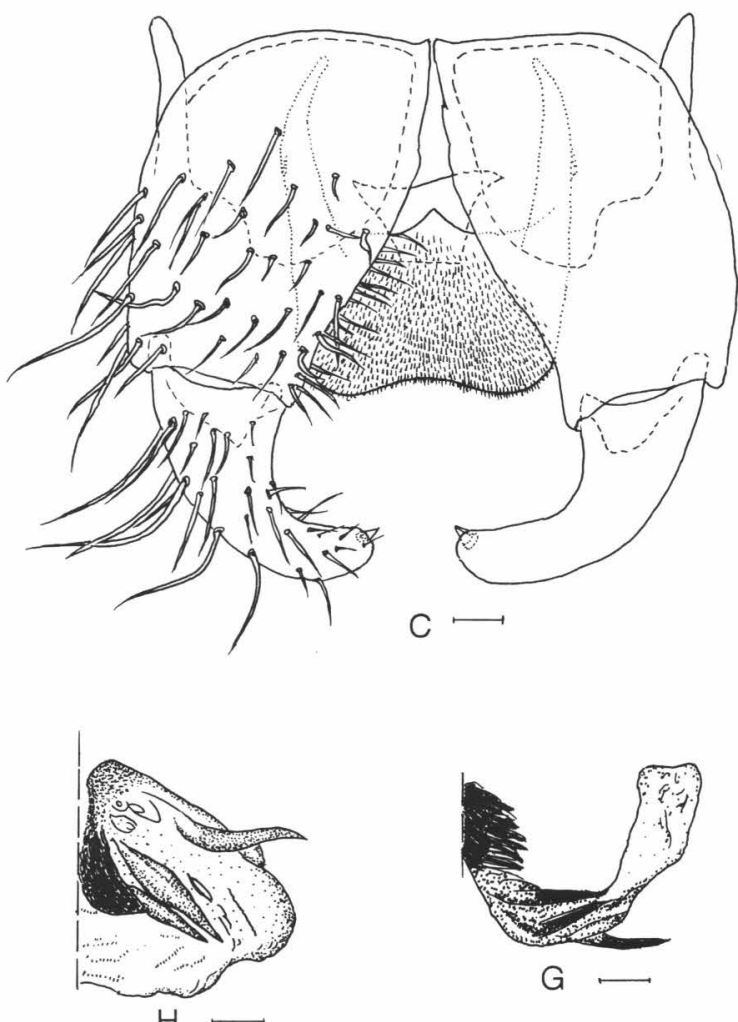

$\mathrm{H}$

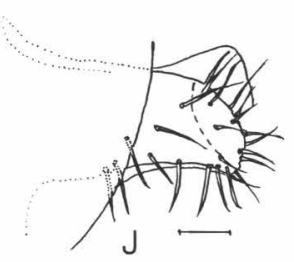

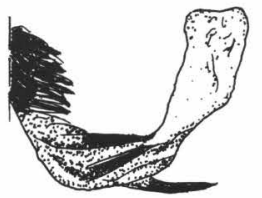

G

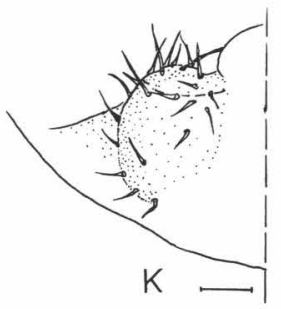

Fig. 2. Male of Simulium (Gomphostilbia) syuhaiense sp. nov. A, 3rd segment of maxillary palp with sensory vesicle (left side and front view); B, basitarsus and 2nd tarsal segment of hind leg showing calcipala and pedisulcus (left side and outer view); C, coxites, styles, ventral plate and median sclerite in situ (ventral view); D, style (right side and ventrolateral view); E, ventral plate and median sclerite in situ (lateral view); F, ventral plate (end view); G, paramere (right side and dorsal view); H, paramere and aedeagal membrane in situ (left side and end view); I, dorsal plate (dorsal view); J and K, 10th abdominal segments and cerci in situ (J, right side and lateral view; K, right side and end view). Scale bars. $0.1 \mathrm{~mm}$ for $\mathrm{B} ; 0.02 \mathrm{~mm}$ for $\mathrm{A}$ and $\mathrm{C}-\mathrm{K}$.

dark brown simple longer hairs. Antenna composed of scape, pedicel and 9 flagellomeres, brownish-black except scape, pedicel and 1st flagellomere dark yellow on ventral surface and mostly light brown on dorsal surface; 1st flagellomere elongate, 1.67 times as long as 2nd flagellomere. Maxillary palp with 5 segments, light brown, proportional lengths of $3 \mathrm{rd}$, 4 th, and 5 th segments $1.00: 1.14: 2.77$; 3rd segment (Fig. 2A) widened apically; sensory vesicle (Fig. 2A) ellipsoidal, 0.24 times as long as 3rd segment, and with very small opening. Thorax. Scutum black, with shiny, whitish to bluish pruinose pattern composed of anterior pair of 
patches on shoulders, longitudinal band along each lateral margin and large patch on prescutellar area; scutum densely covered with dark brown short hairs interspersed with patch of yellow short hairs on each shoulder and several dark brown upright longer hairs on prescutellar area. Scutellum black, with dark brown short hairs and dark brown long upright hairs along posterior margin. Postnotum black, whitish to bluish pruinose and slightly shiny when illuminated at certain angle of light, and bare. Pleural membrane bare. Katepisternum longer than deep, black, with dark short hairs and yellowish-white short hairs. Legs. Color nearly as in female except fore coxa dark yellow to light brown, fore trochanter entirely medium brown, mid basitarsus dark yellow on basal $1 / 3$ or less, and hind tibia yellow on extreme base. Fore basitarsus moderately dilated, 7.11 times as long as its greatest width; hind basitarsus (Fig. 2B) narrow, nearly parallel-sided, 5.50 times as long as wide, and 0.60 and 0.65 times as wide as greatest widths of tibia and femur, respectively; calcipala nearly as long as its basal width, and 0.45 times as wide as greatest width of basitarsus. Pedisulcus well marked. Wing. Length 1.7-1.8 $\mathrm{mm}$; hair covering nearly as in female except subcosta bare. Abdomen. Basal scale black, with fringe of yellow hairs. Dorsal surface of abdomen brownish-black to black except anterior $1 / 2$ of 2 nd segment light to medium brown, covered with dark short to long hairs; segments 2 and 5-7 each with pair of shiny whitish to bluish pruinose dorsolateral patches, of which those on segment 2 broadly connected in middle to each other, those on segments 5 and 6 narrowly connected to each other along anterior margin and those on segment 7 not connected. Genitalia. Coxite in ventral view (Fig. 2C) nearly rectangular, 1.72 times as long as its greatest width. Style in ventral view (Fig. 2C) slender, tapered toward basal $1 / 2$, then nearly parallel-sided, 0.78 times as long as coxite, gently bent inward, with apical spine; style in ventrolateral view (Fig. 2D) nearly parallel-sided from base to basal $1 / 3$, then tapered toward apex. Ventral plate in ventral view (Fig. $2 \mathrm{C}$ ) with body transverse, 0.70 times as long as wide, slightly narrowed posteriorly, with anterior margin produced anteromedially, and posterordorsal margin slightly concave medially, densely covered with microsetae on ventral surface; basal arms of moderate length, slightly diverged, then slightly converged apically; ventral plate in lateral view (Fig. 2E) moderately produced ventrally; ventral plate in end view (Fig. $2 \mathrm{~F}$ ) with each ventrolateral margin rounded, and ventral margin slightly concave medially, densely covered with microsetae on posterior surface. Median sclerite (Fig. 2C, E) thin, platelike, wide. Paramere (Fig. 2G, H) of moderate size, each with 3 distinct long and stout hooks and several smaller ones close together near apex. Aedeagal membrane (Fig. 2H) sparsely setose; dorsal plate (Fig. 2I) weakly sclerotized. Abdominal segment 10 (Fig. 2J, K) without distinct hairs near posterior margin on ventral surface. Cercus (Fig. 2J, K) rounded, with 22 24 hairs.

Pupa. Body length 2.5-2.9 mm. Head. Integument light yellow, moderately covered with small round tubercles on frons and each lateral surface but bare on antennal sheath and ventral surface of face; antennal sheath without any protuberances; face with pair of simple long trichomes with uncoiled apex, and frons with 3 pairs of simple long trichomes with uncoiled apex; 3 frontal trichomes on each side arising close together, subequal in length to one another and nearly as long as or slightly longer than facial one. Thorax. Integument yellow to yellowish-brown, moderately covered with round tubercles, with 3 simple long trichomes with coiled or uncoiled apex dorsomedially, 2 simple long trichomes with uncoiled apices anterolaterally, 1 simple medium-long trichome with uncoiled apex posterolaterally, and 3 simple trichomes with uncoiled apices ( 1 medium-long and 2 short) ventrolaterally on each side. Gill (Fig. 3A) composed of 8 slender thread-like filaments, longer than pupal body, arranged in $3+(1+2)$ +2 filaments from dorsal to ventral, with somewhat swollen transparent organ ventrally (partially broken) at base; dorsal and middle triplets and ventral pair arising directly from short common basal stalk; dorsal triplet composed of 3 individual filaments with very short stalk; middle triplet composed of 1 individual and 2 paired filaments with short stalk, or rarely 3 individual filaments arising at same level; stalk of ventral paired filaments of medium length, slightly thinner than interspiracular trunk, and somewhat thicker than primary stalk of middle triplet which is somewhat thicker than stalk of dorsal triplet; stalk 


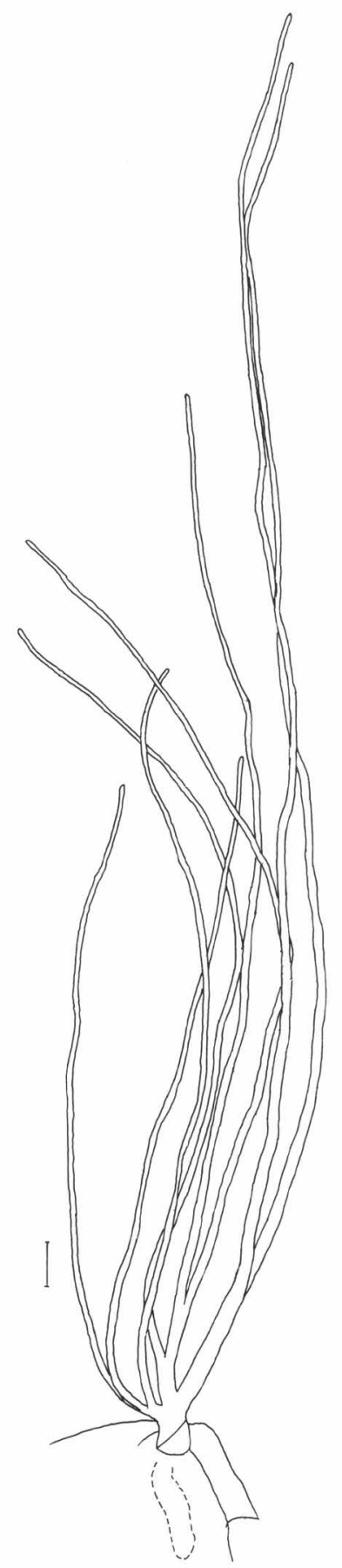

A
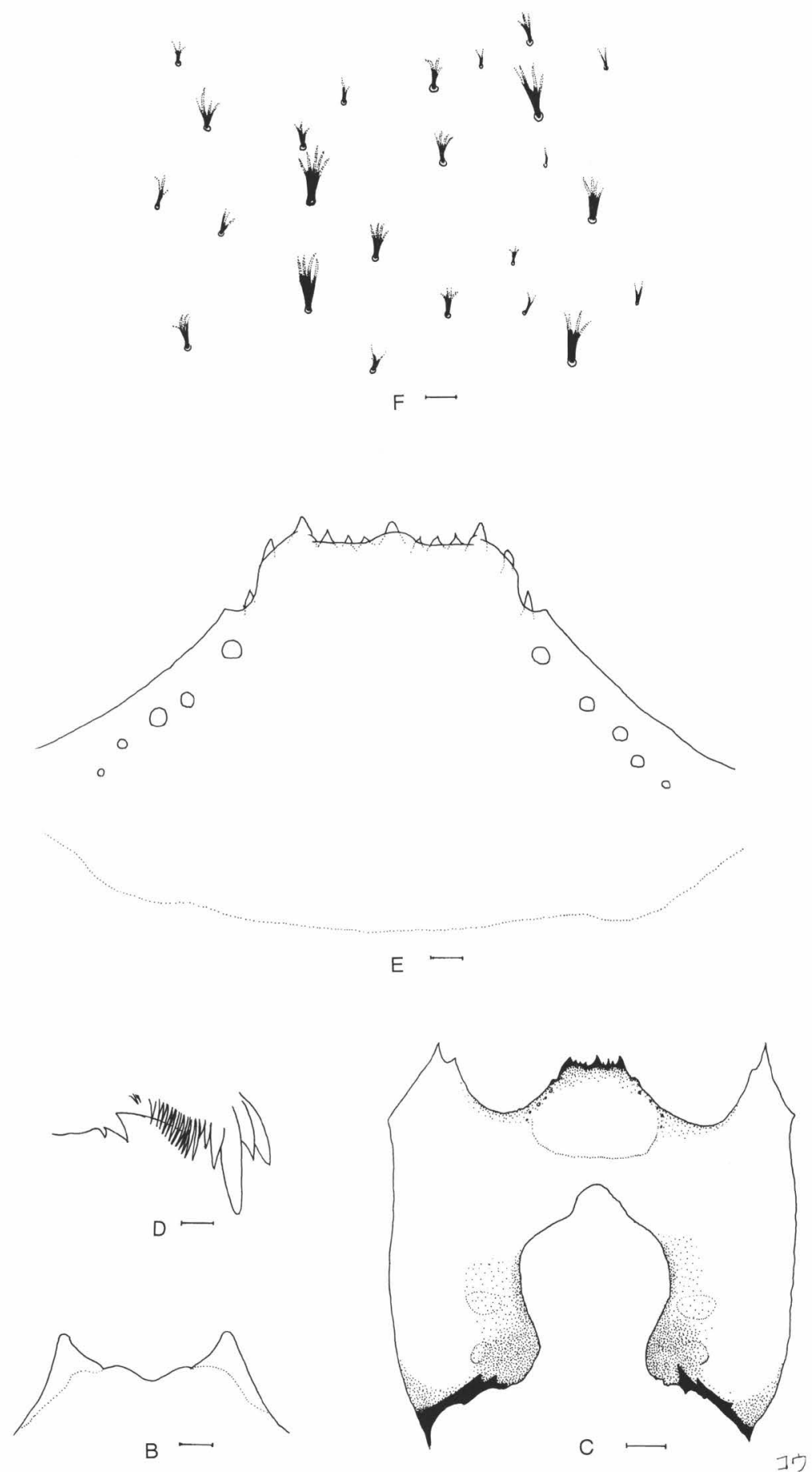

Fig. 3. Pupa and mature larva of Simulium (Gomphostilbia) syuhaiensesp. nov. A and B, pupa; C-F, larva. A, gill filaments (right side and outer view); B, terminal hooks (end view); C, head capsule showing postgenal cleft (ventral view); D, tip of mandible; E, hypostoma; F, dark simple and branched setae on dorsal surface of abdominal segment $8 \mathrm{in} \mathrm{situ.} \mathrm{Scale} \mathrm{bars.} \mathrm{Scale} \mathrm{bars,} 0.1 \mathrm{~mm}$ for A; $0.05 \mathrm{~mm}$ for $\mathrm{C}$; $0.01 \mathrm{~mm}$ for $\mathrm{B}$ and $\mathrm{D}-\mathrm{F}$. 
of dorsal triplet lying against that of lower pair at angle of 90 degrees or slightly more when viewed laterally; all filaments light to medium brown, gradually tapered toward apex; 3 filaments of dorsal triplet subequal in length (1.5-2.0 $\mathrm{mm}$ long) and thickness to one another, those of middle triplet subequal in length (2.0$3.0 \mathrm{~mm}$ long) and thickness to one another, and 2 filaments of ventral pair subequal in length (3.3-4.0 $\mathrm{mm}$ long) and thickness to each other and much longer and thicker than 6 other filaments of dorsal and middle triplets; cuticle of all filaments with well-marked annular ridges and furrows though becoming less marked apically, densely covered with minute tubercles. Abdomen. Dorsally, segments 1 and 2 light brown and without tubercles; segment 1 with 1 simple slender medium-long hair-like seta on each side; segment 2 with 1 simple slender medium-long hair-like seta and 5 very short somewhat spinous setae submedially on each side; segments 3 and 4 each with 4 hooked spines and 1 very short somewhat spinous seta on each side; segment 5 usually lacking spinecombs or rarely with 1 spine; segments 6-9 each with spine-combs in transverse row (though spine-combs on segment 9 somewhat smaller than those on other segments), and comb-like groups of minute spines on each side; segment 9 with pair of distinct coneshaped terminal hooks (Fig. 3B). Ventrally, segment 4 with 1 simple hook and few simple slender very short setae on each side; segment 5 with pair of bifid hooks submedially and few very short simple slender setae on each side; segments 6 and 7 each with pair of bifid inner and simple outer hooks somewhat spaced from each other and few very short simple slender setae on each side; segments $4-8$ with comblike groups of minute spines. Each side of segment 9 with 3 grapnel-shaped hooklets. Cocoon. Wall-pocket-shaped, thinly and neatly woven, extending ventrolaterally; anterior margin somewhat thickly woven, posterior $1 / 2$ with floor roughly or moderately woven; individual threads invisible; $3.3-3.8 \mathrm{~mm}$ long by 1.8-2.6 mm wide.

Mature larva. Body length $4.3-5.3 \mathrm{~mm}$. Body whitish to light grayish-green, with pair of reddish-brown dorsomedial or dorsolateral transverse bands on each of thoracic and abdominal segments though bands on abdominal segments 5,8 and 9 usually connected dorsomedially to each other. Cephalic apotome whitish-yellow to yellowish-brown though surrounding area of each spot somewhat darkened; head spots all negative or partially negative with some spots apparently positive. Lateral surface of head capsule whitish-yellow except eye-spot region whitish and large area between eye-spot region and posterior margin darkened and anteroventral area near eye-spot region often darkened; eyebrow faintly defined; small isolated spot below eye-spot region indistinct or faintly positive. Ventral surface of head capsule (Fig. 3C) whitish-yellow though posterior $1 / 3$ to $1 / 2$ darkened in some larvae; transverse spot on each side of postgenal cleft positive or negative or merged into dark background. Antenna composed of 3 segments and apical sensillum, somewhat longer than stem of labral fan; proportional lengths of 1st, 2nd, and 3rd segments $1.00: 0.90-0.96: 0.86-0.96$; unpigmented secondary annular bands absent. Labral fan with $42-46$ main rays. Mandible (Fig. 3D) with 1st comb-tooth much longer than 2nd comb-tooth, which is slightly longer than 3rd one; mandibular serration composed of 2 teeth ( 1 medium-sized and 1 small); major tooth at acute angle against mandible on apical side; supernumerary serrations absent. Hypostoma (Fig. 3E) with row of 9 apical teeth; median and each corner tooth prominent, subequal in length to each other, and much longer than 3 intermediate teeth on each side; lateral margin smooth; 3-5 hypostomal bristles per side, lying parallel to lateral margin. Postgenal cleft (Fig. 3C) deep (7.80-14.33 times as long as postgenal bridge), rounded laterally and with small rounded apex. Cervical sclerite composed of 2 yellow slender rod-like pieces, not fused to occiput, widely separated medially from each other. Thoracic cuticle bare. Abdominal cuticle almost bare on segments 1 and 2 , and dorsally covered with dark simple and branched ( $2-5$ branches each with transparent apex) setae of various sizes (Fig. 3F) very sparsely on segments 3 and 4 , and moderately on segments $5-9$, and also moderately covered with simple colorless minute setae on each side of anal sclerite of last segment. Rectal scales absent. Rectal papilla compound, each of 3 lobes with 5-7 finger-like secondary lobules. Anal sclerite of usual X-form, with anterior arms slightly shorter than posterior ones, broadly sclerotized at base; accessory sclerite absent. Last abdominal segment expanded ventrolaterally forming double bulges on each 
side, visible as large conical ventral papilla when viewed from side. Posterior circlet with 74-80 rows of up to 14 hooklets per row.

TYPE SPECIMENS. Holotype female (with associated pupal exuviae and cocoon) reared from pupa (preserved in $80 \%$ ethanol), collected from a small slowflowing stream (width $2.0 \mathrm{~m}$, shaded, altitude $210 \mathrm{~m}$ ) densely covered by grasses, Syuhai, Mudan, Pingtung County, Taiwan, 2. II. 2008, by Yao-Te Huang. Paratypes: 2 females, 2 males (all with associated pupal exuviae and cocoons), 5 pupae and 4 mature larvae, same data as those of the holotype; 2 females (with associated pupal exuviae and cocoons) and 5 mature larvae, collected from a small slow-flowing stream (width 3.0-4.0 m, partially shaded, altitude 210 m), Syuhai, Mudan, Pingtung County, Taiwan, 2. II. 2008, by Yao-Te Huang.

ECOLOGICAL NOTES. The pupae and larvae of this new species were collected from fallen tree leaves in the water, together with S. (Gomphostilbia) tuenense Takaoka, S. (Nevermania) aureohirtum Brunetti, S. (Simulium) quinquestriatum (Shiraki), S. (S.) sakishimaense Takaoka, and S. (S.) suzukii Rubtsov.

ETYMOLOGY. The species name syuhaiense refers to the locality, Syuhai, where this new species was collected.

REMARKS. According to the key (Takaoka, 2003), S. (G.) syuhaiense sp. nov. is readily assigned to the batoense speciesgroup within the subgenus Gomphostilbia by having the adult antenna with 11 segments, pleural membrane bare, katepisternum haired, female claw with a large basal tooth (Fig. 1E), male hind basitarsus not enlarged (Fig. 2B), and eight gill filaments (Fig. 3A).

This new species is characterized by the arrangement of the pupal gill filaments: i.e., ventral paired filaments are equal in size to each other and much longer and thicker than the other six filaments, and stalks of the three groups of filaments are arising at the same level from the short common basal stalk (Fig. 3A). This new species shows similarities to the following four known species in many characteristics including the arrangement of the pupal gill filaments, dark femora and tibiae and deep larval postgenal cleft: $S$. $(G$.) hadiae Takaoka, described from Sulawesi (Takaoka, 2003), S. (G.) siamense Takaoka and Suzuki, described from Thailand (Takaoka and Suzuki, 1984), S. (G.) sundaicum Edwards, described form Java (Edwards, 1934), and S. (G.) yaeyamaense Takaoka, described from the Ryukyu Islands (Takaoka, 1991). However this new species is easily distinguished from all these known species by the elongate female sensory vesicle (Fig. 1B) (the relative length of the sensory vesicle against the third maxillary palpal segment is $0.56-0.64$ in this new species and 0.30 0.38 in the four known species). In addition, this new species differs from $S$. $(G$.) hadiae, S. (G.) siamense and $S$. (G.) yaeyamaense in the color pattern of the male scutum (there are a medial non-pruinose vitta and two submedial non-pruinose spots contrasting to the remaining whitish pruinose area on the male scutum of the three known species), and from $S$. $(G$.) sundaicum by the larval abdomen of which posterior segments are moderately covered with dark setae in this new species but lack such dark setae in the latter species.

\section{ACKNOWLEDGEMENTS}

We would like to thank Ms. Chiharu Aoki, Oita University, for her kind help in various ways during this study. This study was in part supported by a Grant-inAid for Oversea Research from the Japan Society for the Promotion of Science (No. 18406011). 


\section{REFERENCES}

Chung, C. L. 1986. A new record of Simulium (Wallacellum) yonakuniense from Lanyu Is., Taitung county, Taiwan (Diptera: Simuliidae). J. Taiwan Mus., 39: 1-10.

Edwards, F. W. 1934. The Simuliidae (Diptera) of Java and Sumatra. Arch. Hydrobiol., 13 Suppl. "Tropische Binnengewässer" 5: 92-138.

Shiraki, T. 1935. Simuliidae of the Japanese Empire. Mem. Fac. Sci. Agric. Taihoku Imp. Univ., 16: 1-90.

Takaoka, H. 1979. The black flies of Taiwan (Diptera: Simuliidae). Pac. Insects, 20: 365-403.
Takaoka, H. 1991. A revisionary note on the blackfly, hitherto called "Simulium (Gomphostilbia) batoense Edwards, 1934" from the Ryukyu Islands, Japan (Diptera: Simuliidae). Jpn. J. Trop. Med. Hyg., 19: 265-273.

Takaoka, H. 2003. The Black Flies (Diptera: Simuliidae) of Sulawesi, Maluku and Irian Jaya. xxii+581 pp., Kyushu University Press, Fukuoka.

Takaoka, H. and Huang, Y. T. 2006. A new species of Simulium (Simulium) (Diptera: Simuliidae) from Taiwan. Med. Entomol. Zool., 57: 219-227.

Takaoka, H. and Suzuki, H. 1984. The blackflies (Diptera: Simuliidae) from Thailand. Jpn. J. Sanit. Zool., 35: 7-45. 